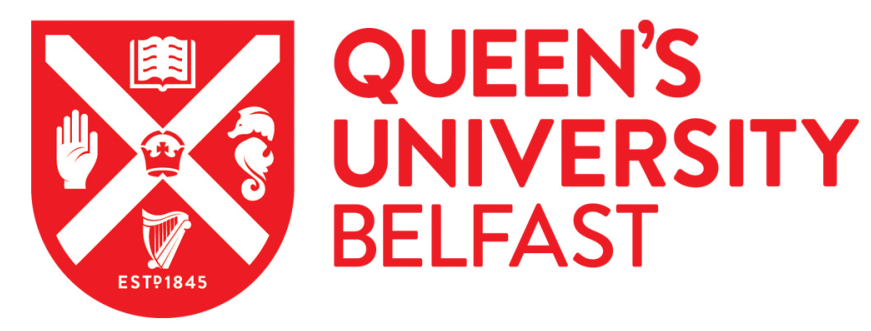

\title{
Numerical considerations for the implementation of a comprehensive composite damage model
}

Chiu, L. N. S., Falzon, B. G., Chen, B., \& Yan, W. (2015). Numerical considerations for the implementation of a comprehensive composite damage model. Paper presented at 2nd Australian Conference on Computational Mechanics, Brisbane, Australia.

Document Version:

Publisher's PDF, also known as Version of record

Queen's University Belfast - Research Portal:

Link to publication record in Queen's University Belfast Research Portal

Publisher rights

Copyright 2016 The Authors

\section{General rights}

Copyright for the publications made accessible via the Queen's University Belfast Research Portal is retained by the author(s) and / or other copyright owners and it is a condition of accessing these publications that users recognise and abide by the legal requirements associated with these rights.

Take down policy

The Research Portal is Queen's institutional repository that provides access to Queen's research output. Every effort has been made to ensure that content in the Research Portal does not infringe any person's rights, or applicable UK laws. If you discover content in the Research Portal that you believe breaches copyright or violates any law, please contact openaccess@qub.ac.uk. 


\title{
Numerical considerations for the implementation of a comprehensive composite damage model
}

\author{
Louis N. S. Chiu' ${ }^{1,2}$, Brian G Falzon ${ }^{3}$, Bernard Chen ${ }^{1}$ and Wenyi Yan ${ }^{1}$ \\ 1, Monash University, Department of Mechanical and Aerospace Engineering, Clayton Campus, \\ Victoria 3800, Australia \\ 2, Cooperative Research Centre for Advanced Composite Structures, 506 Lorimer Street, \\ Fishermans Bend, Victoria, 3207, Australia \\ ${ }^{3}$, Queen's University Belfast, School of Mechanical and Aerospace Engineering, Belfast,
} BT9 5AH, UK

Keywords: Composite Damage, Nonlinear Finite Element

\begin{abstract}
A comprehensive continuum damage mechanics model [1] had been developed to capture the detailed behaviour of a composite structure under a crushing load. This paper explores some of the difficulties encountered in the implementation of this model and their mitigation. The use of reduced integration element and a strain softening model both negatively affect the accuracy and stability of the simulation. Damage localisation effects demanded an accurate measure of characteristic length. A robust algorithm for determining the characteristic length was implemented. Testing showed that this algorithm produced marked improvements over the use of the default characteristic length provided by Abaqus. Zero-energy or hourglass modes, in reduced integration elements, led to reduced resistance to bending. This was compounded by the strain softening model, which led to the formation of elements with little resistance to deformation that could invert if left unchecked. It was shown, through benchmark testing, that by deleting elements with excess distortions and controlling the mesh using inbuilt distortion/hourglass controls, these issues can be alleviated. These techniques contributed significantly to the viability and usability of the damage model.
\end{abstract}

\section{Introduction}

Damage and fracture in a composite laminate are complex phenomena [2], with a multitude of interacting mechanisms which affect the final response [3-7]. The ability to accurately predict the initiation and progression of damage in a structure through finite element modelling, is highly advantageous in the design process for composite structures by reducing the need for expensive and time-consuming subcomponent testing [1].

A high-fidelity 3D material damage model was developed by the authors [1] based on continuum damage mechanics [8]. This model is underpinned by the energy required to create a crack in the laminate ply. Material nonlinearity and load-history effects in the material response were also incorporated. Multiple physically-based damage modes are featured in the model. The extent of damage caused by each damage mode is assessed based on local loading conditions [9]. Multiple damage modes can affect a region concurrently and their interactions are accounted for. This model was implemented into Abaqus/Explicit [10] as a custom VUMAT subroutine which allows a userspecified material response in the finite element analysis.

This paper presents a discussion regarding the numerical issues that arise due to the strain softening nature of the constitutive relationship used in this model as well as the use of reduced integration linear solid finite elements. Attention is focussed on the introduction of a robust characteristic length 
algorithm, the deletion of elements close to failure as well as the suppression of zero-energy (hourglass) modes.

\section{Characteristic length}

Finite element analysis of a material that has a strain-softening response is strongly mesh dependent [11]. The softening response leads to localisation of damage where a fracture surface manifest as a layer of softened or failed elements. The thickness of this layer is dependent on the mesh density. A mesh sensitivity study, on a $2 \mathrm{~mm}$ sided cube loaded in longitudinal tension, was performed with $1^{3}$, $2^{3}, 3^{3}, 4^{3}$ and $5^{3}$ elements respectively as shown in Fig. 1 . The models were loaded in tension longitudinally until destruction. These models had uniform material properties and artificial stress concentrator that encourage damage initiation at a pre-defined location was not required.
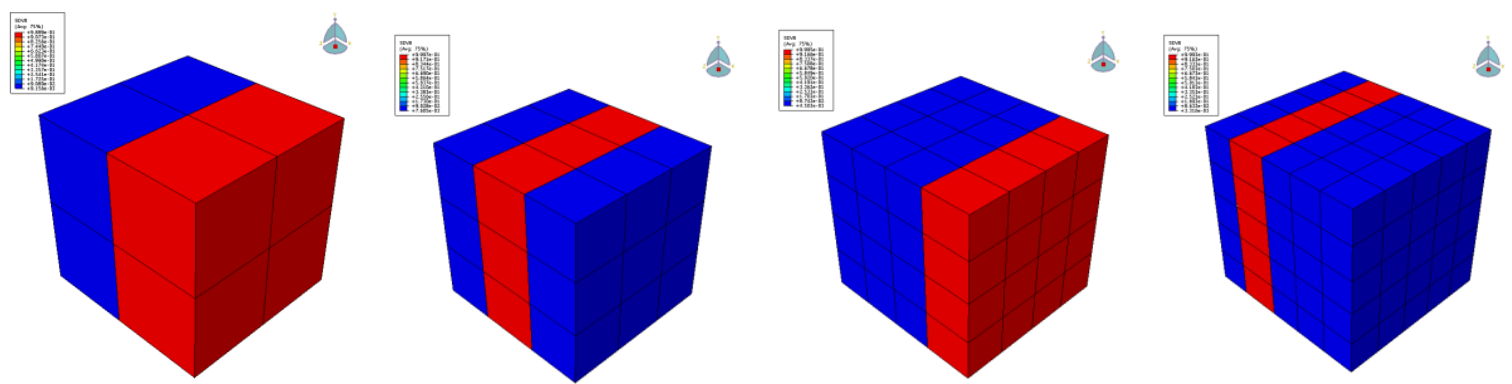

Fig. 1: Different meshes that represent the same fracture surface (red) but with different failed volume due to the different mesh density.

The total energy absorbed in the creation of this damage is dependent on the size of the elements that make up the mesh:

$$
E_{\text {absorbed }}=\sum_{i=\text { damaged elements }} V_{i} \int_{0}^{\text {failure }} \sigma_{i}(\varepsilon) \cdot \varepsilon_{i} d \varepsilon
$$

With increasing mesh refinement, the energy in Eq. (1) approaches zero [12] which is unphysical. Oliver [13] resolves this issue by scaling the experimentally determined critical energy release rate $\left(G_{\text {mode }}^{\text {dir }}\right)$ by a characteristic length $\left(l_{\text {mode }}\right)$ and using the resulting $g_{\text {mode }}^{\text {dir }}$ to replace $E_{\text {absorbed }}$.

$$
g_{\text {mode }}^{\text {dir }}=\frac{G_{\text {mode }}^{\text {dir }}}{l_{\text {mode }}}
$$

It was shown that by using the resulting critical volumetric strain energy $\left(g_{\text {mode }}^{\text {dir }}\right)$ rather than $G_{\text {mode }}^{\text {dir }}$ in the constitutive equations, mesh dependence of total energy absorption was effectively suppressed. The progression of the damage parameter $\left(d_{\text {mode }}^{\text {dir }}\right)$ was dependent on $g_{\text {mode }}^{\text {dir }}$ and the local strain.

$$
d=f\left(g_{\text {mode }}^{\text {dir }}, \varepsilon\right)
$$

This damage parameter was then used to control the constitutive equations via:

$$
\sigma=E_{0}(1-d) \varepsilon
$$

For a pristine material, $d_{\text {mode }}^{\text {dir }}$ was set to zero. The material became progressively softer as the damage, as represented by the increasing damage parameter, increased. When it reached unity, the material was considered to have failed completely. 
The characteristic length for a solid element was defined as the ratio between the volume of the element and the effective crack area [13].

$$
l_{\text {mode }}=\frac{V}{A}
$$

The elemental volume $(V)$ can be obtained readily from the FE simulation. However, the calculation of the fracture surface area $(A)$ is more complex due to the fracture surface orientation being dependent on the damage mode being activated, the ply layup orientation, the element geometry as well as local loading conditions. As a result, the characteristic length algorithm must be able to account for an arbitrarily oriented crack surface which is poorly handled in existing implementations. For example, the Abaqus [10] inbuilt characteristic length is simply the cube root of the elemental volume. This approach disregards the fracture plane orientation and the element shape. The results are shown in Fig. 2, which clearly demonstrates the significant mesh dependence.

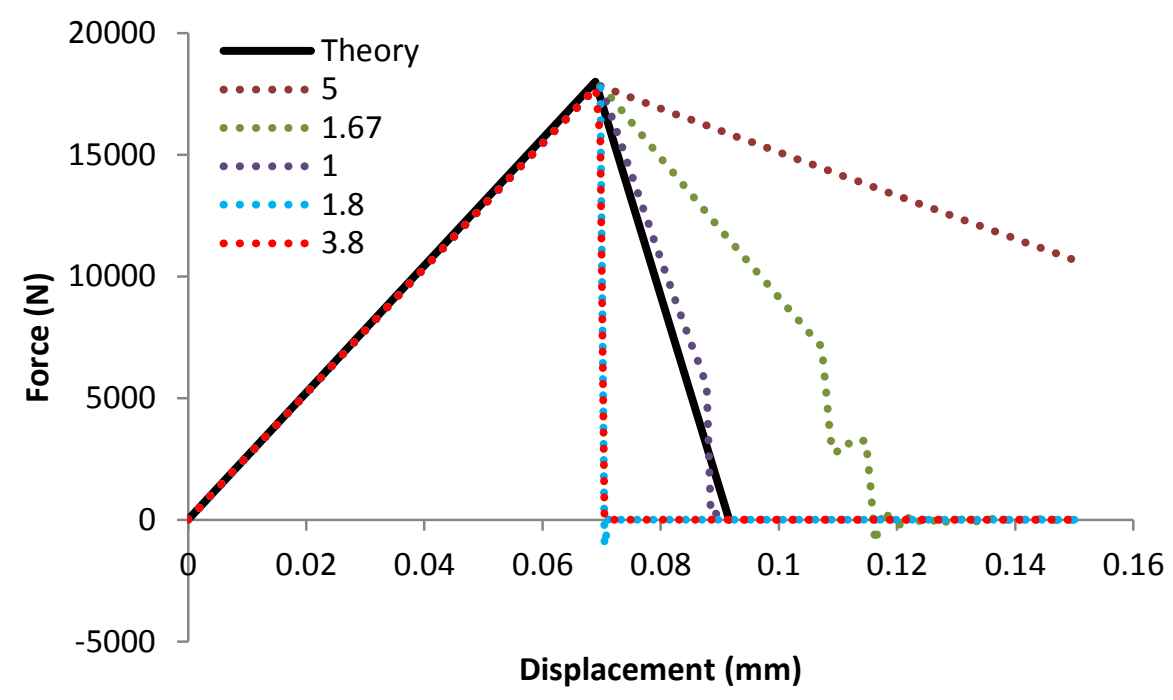

Fig. 2: Force response of simple tensile test case with varying elemental aspect ratio using the Abaqus default characteristic length calculation

An algorithm was proposed to calculate the characteristic length, accounting for the aforementioned factors. The fracture surface is defined by a unit normal vector $(\hat{n})$ in an arbitrary hexahedral element. This normal vector combines information about the material layup as well as the damage mode being activated. The algorithm determines the points $\left(p_{k}\right)$ where the fracture plane intersects with the elemental boundary formed by connecting adjacent nodes (Fig. 3). The triangular areas $\left(A_{l}\right)$ enclosed by adjacent intersection points $\left(p_{k}\right)$ and the centre are then determined. Summing these, the total fracture plane area can be obtained.

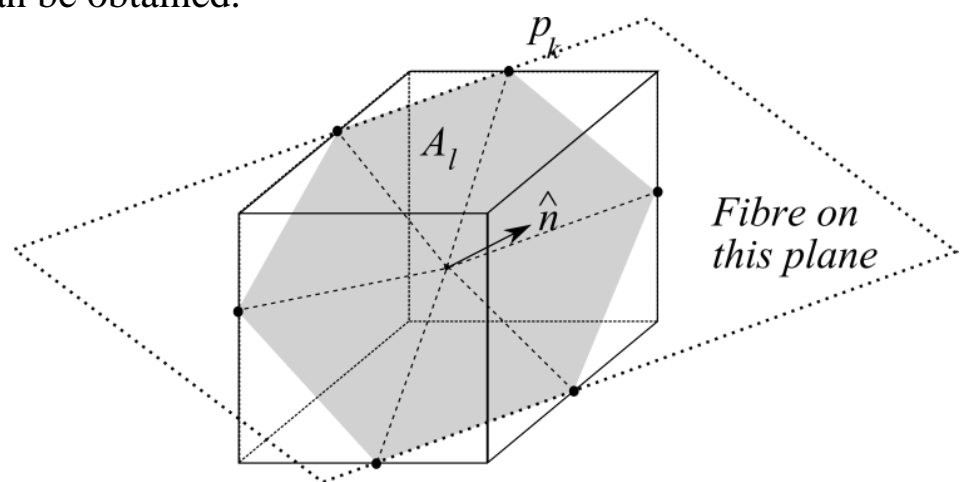

Fig. 3: Definition of unit normal vector $(\hat{n})$ and points of edge intersection $\left(p_{k}\right)$ for an arbitrary fracture plane (shaded) within a hexahedral element. 
Fig. 4 shows the improvement of the proposed algorithm for the same simple tensile test case. The results were largely independent of mesh density. Some deviations were observed near the point of material failure, particularly for large aspect ratios. This is a consequence of adopting a strain softening approach which leads to elements experiencing very large strains and the infinitesimal strain assumption in the model begins to break down.

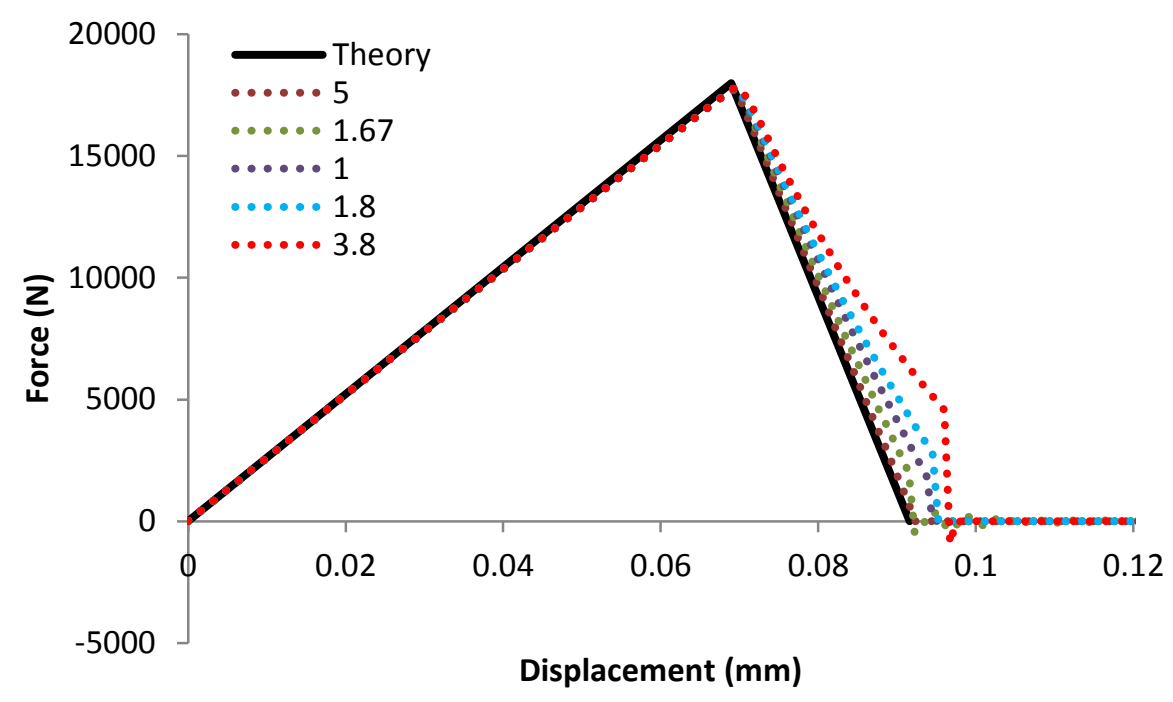

Fig. 4: Force response of simple tensile test case with varying elemental aspect ratio using the proposed characteristic length algorithm

\section{Element deletion}

As damage progresses in an element, the stiffness of the element $(E)$ begins to degrade from the pristine value $\left(E_{0}\right)$ based on the damage parameter $(d)$ in accordance with Eq. (6) [1].

$$
E=E_{0}(1-d)
$$

As a result, the resistance against deformation reduces with increasing damage. As the element approaches failure, the resistance to deformation also approaches zero. These very soft elements can potentially undergo very large and unrealistic deformations and adversely affecting the stability of the finite element process. These elements may also become non-convex or inverted. This is a more severe issue and Abaqus has inbuilt mechanisms which will abort the simulation upon the detection of this phenomena.

A popular method for dealing with these overly soft elements is to remove them from the simulation. This feature has been implemented in various commercial finite element packages including Abaqus [10], LS-DYNA [14] and PAM-CRASH [15]. These implementations are generally reliant on the damage parameter to determine whether to remove an element. However, the use of this simplistic deletion criterion can have a significant adverse effect on the simulation results as deletion of the elements becomes very periodic, particularly for a structured, regular mesh (mostly rectangular elements of approximately the same size), leading to large spikes in the force response. Furthermore, failure of the matrix in the composite ply does not necessarily mean that the ply cannot resist further loading in all directions. A purely damage parameter based deletion criteria would cause the premature removal of elements and hence an artificial reduction in the energy dissipation. An element deletion criterion was developed to address these issues. 


$$
\text { delete element when either }\left\{\begin{array}{cc}
(i) & d_{\text {fibre }}>0.99 \\
(i i) & 0.8>\operatorname{det}(F) \text { or } \operatorname{det}(F)>1.6
\end{array}\right.
$$

Condition (i) in Eq. (7) represents the fibre-dominated failure mode. As the composite is strongest in the fibre direction, total failure can be assumed to occur when the fibres have failed. On the other hand, condition (ii) is a measure of the change in volume of the element undergoing deformation.

Large volume changes over a single increment would be indicative of an element that has lost most of its stiffness and hence should be deleted. The limits strike a balance between removing excessive deformation and preventing premature removal of elements. Fig. 5 shows the effectiveness of the proposed criteria over a purely damage parameter based criteria similar to that implemented natively in the finite element package.

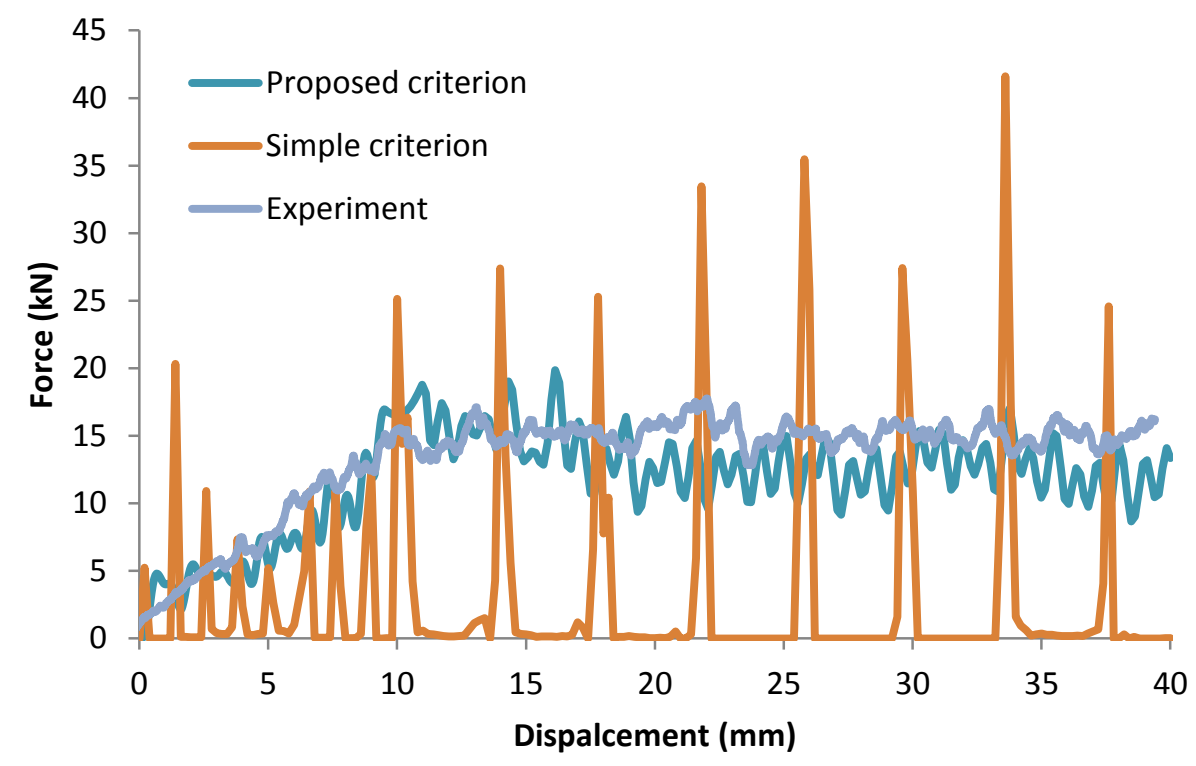

Fig. 5: Effect of element deletion criterion on a typical triggered tube specimen.

The simple criterion yielded force response results which were a series of singular force spikes. This was a result of entire layers of elements being deleted simultaneously. When an entire layer of elements are removed, the resistance to loading is removed, causing the zero force between the spikes. When the load reaches the next layer of elements, a sudden re-introduction of resistance causes the large force spike. As loading increase, the layer fails and the process repeats itself. The spacing between the force spikes is directly related to the length of the element in the loading direction, causing the solution to be strongly mesh dependent. The proposed criterion effectively resolves these issues and yields a force response curve which is continuous and correlates well with experimental observations.

\section{Hourglass effect and distortion control}

Linear reduced integration solid elements were used in the finite analysis as they offer a good balance between good accuracy and computational efficiency. However, reducing the number of integration points creates modes of deformation which do not contribute to the strain energy within the element [16]. The element does not resist these modes of deformation and hence they propagate freely throughout the mesh, creating an unrealistic response. This is exacerbated by the reduction of elemental stiffness as damage progresses. As a result, damaged elements were particularly susceptible to hourglass modes. If left unchecked, unrealistic and excessive distortion will occur, particularly on the elements near the crush front. 
Abaqus [10] contains built-in controls that suppress hourglass deformation modes. This is achieved through the introduction of resistive stresses against these deformation modes. Furthermore, element distortion control is also available to prevent the element from inverting or otherwise distorting excessively. Resistive forces are provided to the nodes to counter the unwanted deformation.

A cylindrical crush test case was used to gauge the effect of hourglass and distortion controls. Four different configurations were tested:

- $\mathrm{NDH}$ - neither distortion nor hourglass control were applied.

- $\mathrm{DC}$ - distortion control only.

- $\mathrm{HG}$ - enhanced hourglass control only.

- $\mathrm{DC}+\mathrm{HG}$ - both distortion and hourglass control were applied.

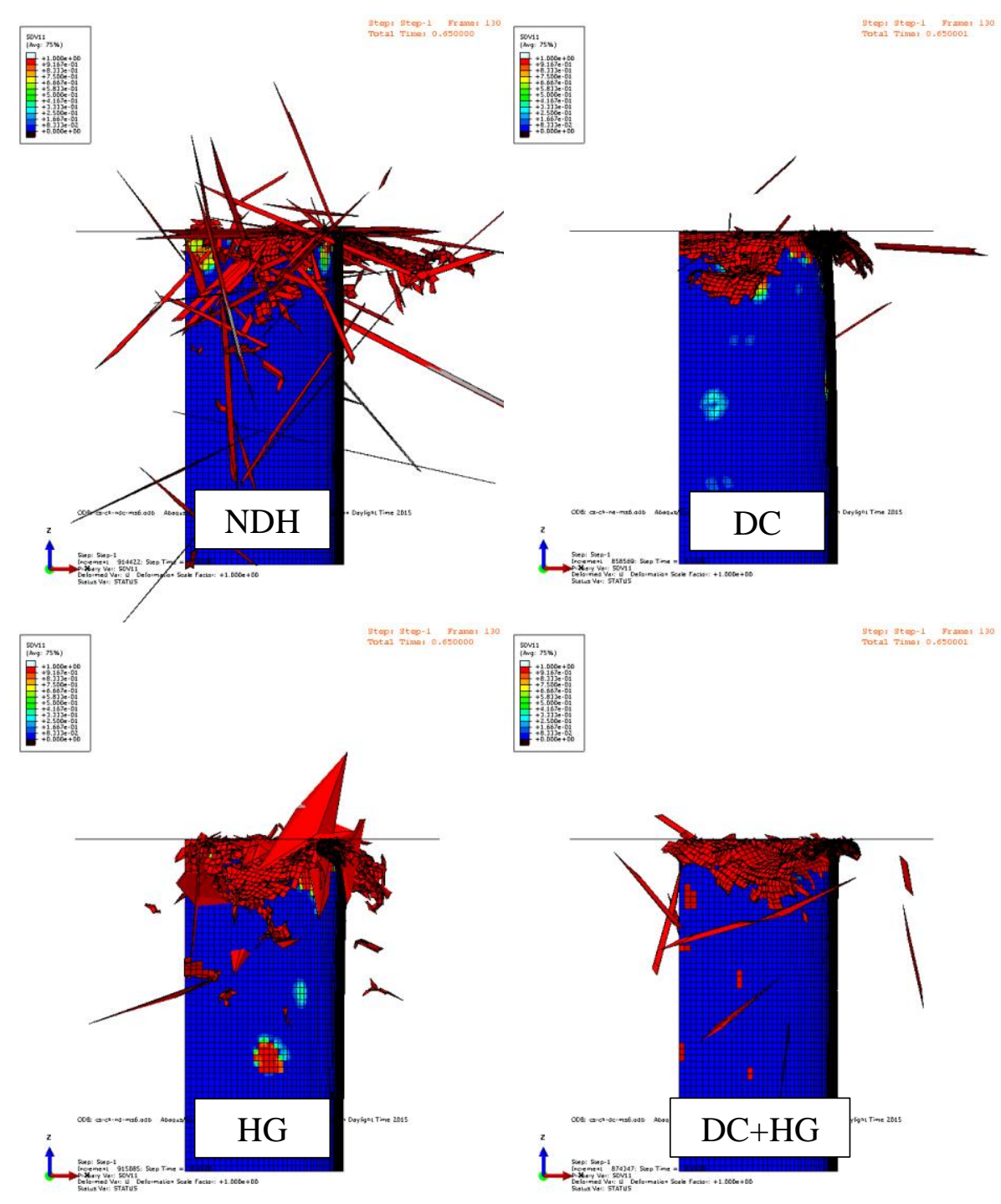

Fig. 6: Effect of hourglass (HG) and distortion (DC) controls on overall deformation.

Fig. 6 shows the overall deformation of the test case while Fig. 7 shows the resulting force response. Overall, the DC+HG case was best. The deformation was well controlled and the force response was free from large spikes and troughs. On the opposite end of the spectrum, the NDH test case clearly demonstrated the proliferation of severely distorted elements as no numerical controls had been applied. Numerous large lance-like elements obscured the crush front. Substantial amount of noise was also observed in the force response. The DC case yielded similar overall deformation compared with the $\mathrm{DC}+\mathrm{HG}$ case. However, the force response contained spikes and troughs that were largest 
of all test cases. The HG test case contained a smaller number of severely distorted elements and the force response was largely identical to that of the NDH case.

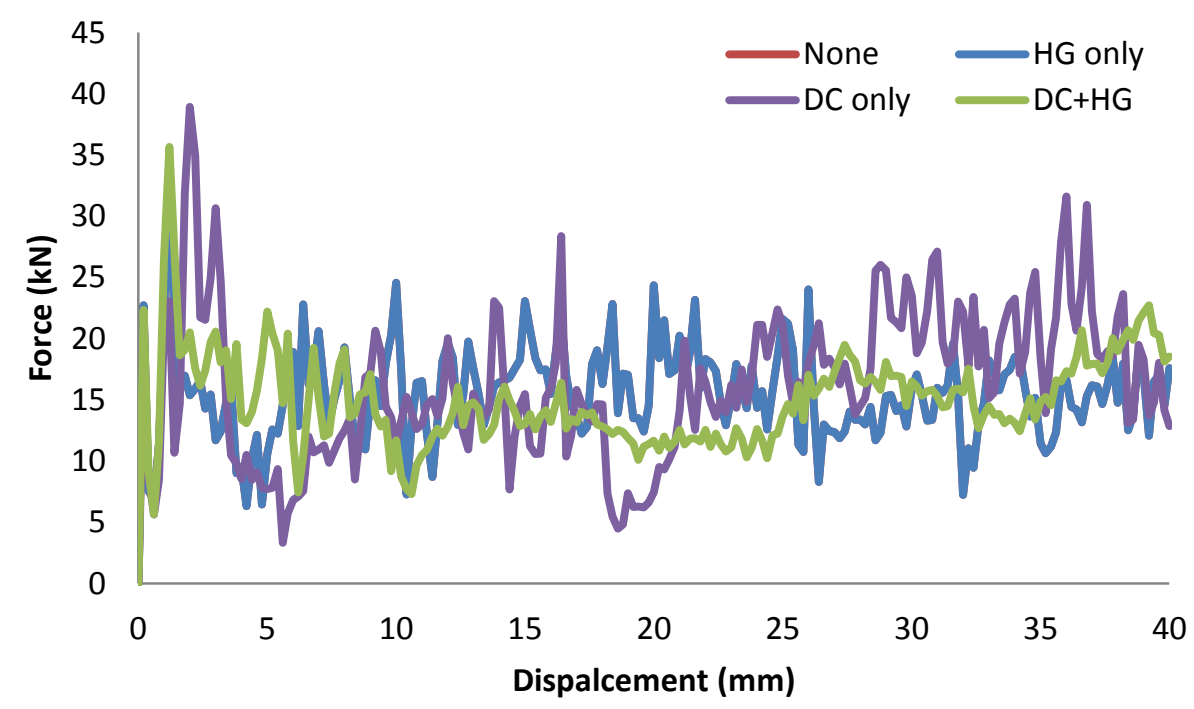

Fig. 7: Effect of hourglass (HG) and distortion (DC) controls on the force response.

These results show that hourglass control and distortion must both be used to achieve suppression of unrealistic response. The effect of this is particularly noticeable in the region of relatively flat force response during the steady-state crushing of the tube body.

Table 1: Effect of hourglass and distortion control on simulation runtime.

\begin{tabular}{lcccc}
\hline Simulation time relative to & NHD & HG & DC & D+H \\
\cline { 2 - 5 } NDH case & 1.000 & 1.026 & 0.970 & 0.993 \\
\hline
\end{tabular}

It was interesting to note that the use of hourglass and distortion controls has a negligible effect on the overall runtime of the simulation, as shown in Table 1. It was likely that although additional CPU cycles were required to apply these controls, this was offset by the overall increase in the increment time step. Needle-like elements, which are supressed by these controls, reduce the stable time increment as the time for a stress wave to propagate across the element reduces.

\section{Concluding remarks}

Three different issues affecting the implementation of a high fidelity material damage model for the simulation of composite structures were discussed. A robust algorithm to calculate the characteristic length for an element with an arbitrarily oriented internal fracture surface was presented and demonstrated to effectively suppress mesh dependency. An element deletion criterion was tailored to the needs of the damage model and was shown to be able to effectively suppress numerical noise. Finally, it was demonstrated that both hourglass and distortion controls were necessary for the suppression of numerical noise and unrealistic deformation. Interestingly, the application of these controls did not adversely affect the computational run time.

\section{Reference}

[1] Chiu, L.N.S., B.G. Falzon, R. Boman, B. Chen, and W. Yan, Finite element modelling of composite structures under crushing load. Composite Structures, 2015. 131(0): p. 215-228. 
[2] Chiu, L.N.S., B.G. Falzon, D. Ruan, S. Xu, R.S. Thomson, B. Chen, and W. Yan, Crush responses of composite cylinder under quasi-static and dynamic loading. Composite Structures, 2015. 131(0): p. 90-98.

[3] David, M., A. Johnson, and H. Voggenreiter, Analysis of Crushing Response of Composite Crashworthy Structures. Applied Composite Materials, 2013. 20(5): p. 773-787.

[4] Waimer, M., D. Kohlgrüber, D. Hachenberg, and H. Voggenreiter, Experimental study of CFRP components subjected to dynamic crash loads. Composite Structures, 2013. 105(0): p. 288-299.

[5] Siromani, D., G. Henderson, D. Mikita, K. Mirarchi, R. Park, J. Smolko, J. Awerbuch, and T.-M. Tan, An experimental study on the effect of failure trigger mechanisms on the energy absorption capability of CFRP tubes under axial compression. Composites Part A: Applied Science and Manufacturing, 2014. 64(0): p. 25-35.

[6] Palanivelu, S., W. Van Paepegem, J. Degrieck, J. Van Ackeren, D. Kakogiannis, D. Van Hemelrijck, J. Wastiels, and J. Vantomme, Experimental study on the axial crushing behaviour of pultruded composite tubes. Polymer Testing, 2010. 29(2): p. 224-234.

[7] Palanivelu, S., W.V. Paepegem, J. Degrieck, J. Vantomme, D. Kakogiannis, J.V. Ackeren, D.V. Hemelrijck, and J. Wastiels, Crushing and energy absorption performance of different geometrical shapes of small-scale glass/polyester composite tubes under quasi-static loading conditions. Composite Structures, 2011. 93(2): p. 992-1007.

[8] Chaboche, J.-L., Continuous damage mechanics - A tool to describe phenomena before crack initiation. Nuclear Engineering and Design, 1981. 64(2): p. 233-247.

[9] Puck, A. and H. Schürmann, Failure analysis of FRP laminates by means of physically based phenomenological models Composites Science and Technology, 1998. 58(7): p. 1045-1067.

[10] SIMULIA, Abaqus Documentation version 6.11. 2011: SIMULIA (Dassault Systems).

[11] Bažant, Z. and B. Oh, Crack band theory for fracture of concrete. Materials and Structures, 1983. 16(3): p. 155-177.

[12] Jirasek, M. and Z.P. Bazant, Inelastic Analysis of Structures. 2002: John Wiley \& Sons.

[13] Oliver, J., A consistent characteristic length for smeared cracking models. International Journal for Numerical Methods in Engineering, 1989. 28(2): p. 461-474.

[14] Hallquist, J.O., LS-DYNA theory manual. 2006, Livermore: Livermore Software Technology Corporation.

[15] Johnson, A.F. and M. David, Failure mechanisms in energy-absorbing composite structures. Philosophical Magazine, 2010. 90(31): p. 4245 - 4261.

[16] Bathe, K.J., Finite element procedures. 1996: Prentice Hall. 